\title{
Differences between low level laser therapy and triamcinolone acetonide kenalog on healing of recurrent aphthous ulceration
}

\author{
Hadeel Salman ${ }^{1}$, Muhannad A. Kashmoola ${ }^{2}$, Mukaram M Al-Waiz ${ }^{3}$, Tahani A. Al-Sandooq ${ }^{4}$. \\ Dental Health Center, right bank, Ninavah Directorate of Health ${ }^{1}$; College of Dentistry ${ }^{2}$; College of \\ Medicine, University of Baghdad ${ }^{3}$; College of Dentistry, Mosul University ${ }^{4}$.
}

(Ann. Coll. Med. Mosul 2008; 34(1): 35-41).

Received: $22^{\text {nd }}$ Oct 2007; Accepted: $20^{\text {th }}$ Feb 2008.

\begin{abstract}
:
Aim of the Study: The Expected benefit is comparison between new high technical arena low level laser (LLLT) and conventional treatment (triamcinolone acetonide kenalog) and select the most effective and faster method for treatment by assessing clinically the effect of these two methods on healing process of recurrent aphthous ulceration.
\end{abstract}

Subjects, materials and methods: A prospective study of 34 patients, age range 11-45 years, with RAU lesions were divided into: Control group: RAU patients without any treatment.

Group I: RAU irradiated with 1.5 Joule laser into two doses (in alternative day).Group II: RAU given triamcinolone acetonide kenalog in orabase daily in two doses. The results obtained account for duration of lesions, size measurement, pain symptoms, and presence of erythema in three visits.

Results: Clinically the mean duration of ulcers healing did not differ widely from control group. The pain sensation of RAU that was treated decreased. Statistically, there is no significant difference in the healing process of RAU treated by LLLT and treated by triamcinolone acetonide kenalog.

Conclusion: low level laser therapy is biomodulation (biostimulation and bioinhibition).Topical triamcinolone is a glucorticoid that has anti-inflammatory and anti proliferative effects. Clinically they slightly decreased the normal time of healing of this immune dysregulating lesion, but there is no superior difference in clinical effects between these two methods.

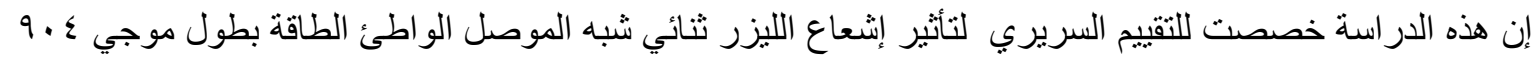

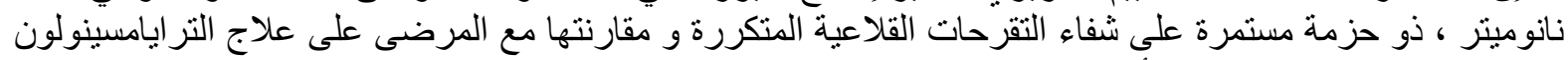

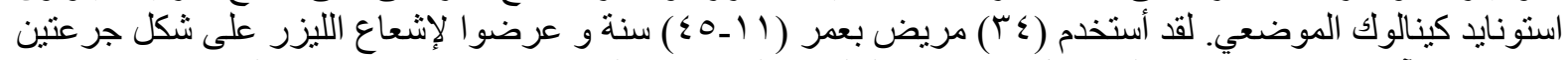

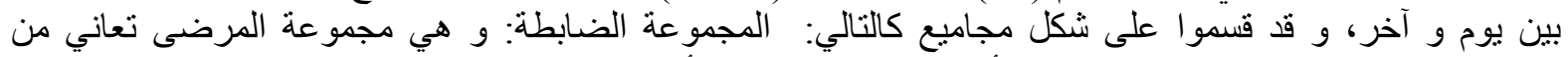

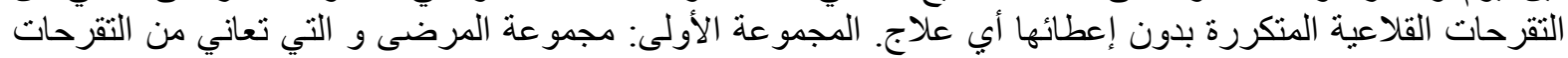

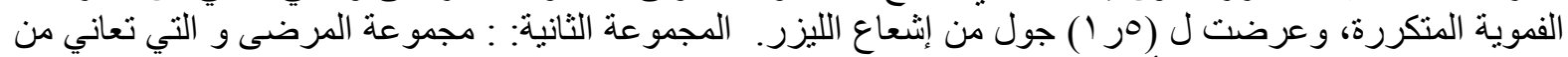

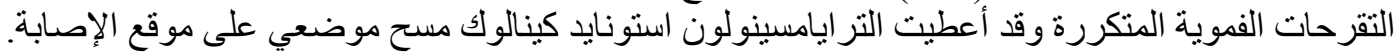

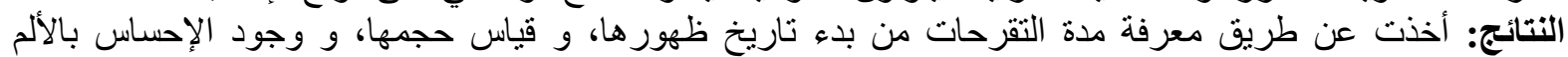

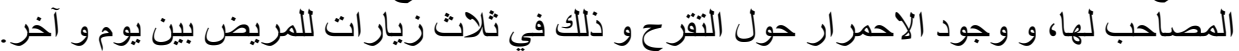

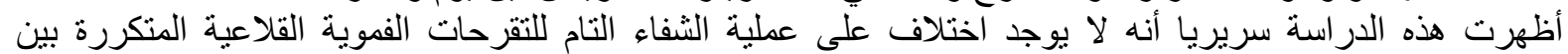

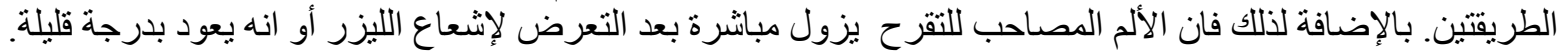

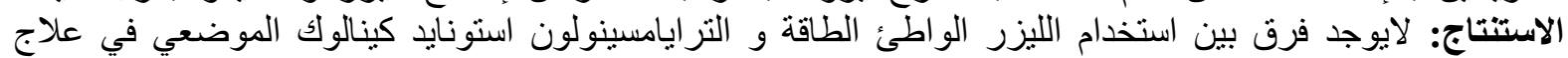
التقرحات الفموية القلاعية. 
A phthae typically are small, round or ovoid ulcers with a circumscribed margin, erythematous halo and yellow or grey floor ${ }^{(1)}$. Aphthous ulcers are among the most common oral lesions in general practice with a frequency of up to $20 \%$ and recurrence rates as high as $50 \%$, with higher prevalence in high socio-economic classes. The ulcers, which usually occur on non keratinized oral mucosa, can cause considerable pain and may interfere with eating, speaking and swallowing. The lesions are confined to the oral mucosa and begin with prodromal burning any time from 2 to 48 hours before an ulcer appears. During this initial period a localized area of erythema develops. Within hours, a small white papule forms, ulcerates, and gradually enlarges over the next 48 to 72 hours. ${ }^{(2)}$.

Recurrent aphthous ulcer (RAU) is classified on the basis of ulcer size and number as minor, major and herpitiform. The cause of RAU is idiopathic in most patients. The most likely precipitating factors are local trauma and stress; Other associated factors include nutritional deficiencies, food allergies, genetic predisposition, immune disorders, use of certain medications, HIV infection and systemic diseases ${ }^{(2,3)}$.

Histologically, aphthae are mucosal ulcerations with a mixed inflammatory infiltrate ${ }^{(4)}$. Numerous studies have been conducted on the immunopathogenesis of RAU and there is good evidence of immune dysregulation. It has been postulated that, in the presence of a local or systemic stimulus, the epithelial cells become targets for the cytotoxic action of lymphocytes and are subsequently destroyed. Current evidence would suggest that RAU is not an autoimmune disease. The immunopathogenesis of this common disorder, however, is yet to be elucidated ${ }^{(3-5)}$.

The primary goals of therapy of RAU are relief of pain, reduction of ulcer duration and restoration of normal function. Current treatments are palliative and focus on pain reduction and acceleration of healing process ${ }^{(2}$, 6).

Topical corticosteroids such as hydrocortisone hemisuccinate, triamcinolone acetonide paste and beclomethasone dipropionate are effective and have two modes of action; anti inflammatory action and specific blocking effect of T-lymphocyteepithelial cell interaction. Most steroids will provide short term pain relief, and some have the problem of being prescription medications, being costly and having the potential for significant side effects and systemic implications ${ }^{(7-9)}$.

Low level laser therapy (LLLT) is based on the concept that certain low level doses of specific coherent wavelengths can turn on off certain cellular components or functions. Dentists have been administering LLLT to their patients as an aid in healing, reducing pain and swelling, and controlling oral infections for at least the past three decades. The oral aphthous ulceration is one of these mucous membrane diseases that was treated by LLLT and many attempts were done to show the efficacy of certain doses of soft laser on the healing process without any side effect ${ }^{(10-12)}$. Other researchers claimed that low level laser 
produced rapid reduction of lesion size with resolution of edema and erythema ${ }^{(13)}$.

\section{Subjects, Materials and Methods:}

Subjects: thirty four Iraqi patients have RAU only, they were otherwise healthy. These patients were requested to refrain from the use of any medicaments throughout the trial. They were divided into:

Control group: were 12 patients with RAU only and should not have other systemic disease in which RAU is a part of its findings.

\section{The study samples consist of:}

- Group I: included 11 patients suffering from RAU only, they were irradiated by1.5 Joule continuous mode laser (time of exposure: $5 \mathrm{~min}$ ).

- Group II: included 11 patients suffering from RAU only, they were given triamciolone acetonide kenalog in orabase.

\section{Materials:}

Laser apparatus a 904 nanometer GalliumArsenide diode laser, the emission used is continuous mode, the average power in optic fiber is 5 milli watts, thus dose measurement in each session was 1.5 joule according to equation:

Energy (Joule) = average power $($ Watt $) \times$ time of radiation (second)

$\mathrm{E}=0.005 \mathrm{~W} \times 300 \mathrm{sec}=1.5 \mathrm{~J}$

- Triamcinolone acetonide kenalog in orabase $1 \mathrm{mg}(0.1 \%)$ dental past.

\section{Methods:}

group-I were given two doses for each lesion in alternative days.

The optic fiber end of laser device applied directly perpendicular to the ulcerative lesion in a manner that does not traumatize the area.
Group- II were given two daily doses of triamcinolone acetonide kenalog in orabase applied topically and directly to the ulcerated area without weeping it.

The patients were examined every two days (for three visits), and in each visit patients examined clinically to evaluate healing process via recording the duration and size of ulcers in millimeters, presence of erythema around the lesions and pain recorded by patients' self-evaluation.

\section{Statistical analysis:}

Data collected, tabulated and statistically analyzed and compared between the groups using statistical measure: ANOVA test was used to compare the mean of duration and mean of size of lesions between the groups. Chi-Square was used to compare the pain and erythema between the groups.

\section{Results:}

Thirty four patients with RAU lesions, age range 11-45 years, males 17 and females 17 . Tables 1, 2 and 3 have shown control and study groups in first, second and third visits respectively:

The Control Group: twelve patients with idiopathic RAU and not taking any medical treatment during the study.

Group I: twenty one RAU in 11 patients were irradiated by $1.5 \mathrm{~J}$ of laser. The mean duration of lesion after two doses of laser irradiation was $3.75 \pm 3.89$ days, the mean size of ulcer has been reduced. The pain sensation is decreased after laser irradiation however; this is a temporary relief and pain regain in low intensity in next visit (33.3\%). The presence of erythema around the ulcer was decreased 
from $95.2 \%$ in first visit to $25 \%$ after two doses of laser irradiation.

Group II: thirteen RAU in 11 patients. Clinically, the mean duration of lesion was reduced to $1.92 \pm 3.25$ days in third visit. The mean size of ulcer has been reduced to $0.57 \pm$ 1.18 millimeter.

In third visit, the pain sensation also disappeared in all patients. The presence of erythema around the ulcer was decreased from $61.5 \%$ to $7.7 \%$ after application of triamcinolone acetonide kenalog.

Statistically, there is no significant difference in duration and size of ulcer in different groups for each visit (first, second, and third). Also there is no significant relation between the presence of pain and erythema in each visit $(P$ value $>0.05$ )

Table- 1: statistical analysis among different groups according to duration, size, pain and erythema in first visit (before any treatment).

\begin{tabular}{|c|c|c|c|c|c|c|c|c|c|c|c|c|}
\hline \multirow[b]{3}{*}{ Groups } & \multicolumn{2}{|c|}{ Duration(days) } & \multicolumn{2}{|c|}{ Size $(m m)$} & \multicolumn{4}{|c|}{ pain } & \multicolumn{4}{|c|}{ erythema } \\
\hline & \multirow[t]{2}{*}{ Mean } & \multirow{2}{*}{ SD } & \multirow[t]{2}{*}{ Mean } & \multirow[t]{2}{*}{ SD } & \multicolumn{2}{|c|}{ positive } & \multicolumn{2}{|c|}{ negative } & \multicolumn{2}{|c|}{ positive } & \multicolumn{2}{|c|}{ negative } \\
\hline & & & & & $\mathrm{N}$ & $\%$ & $\mathrm{~N}$ & $\%$ & $\mathrm{~N}$ & $\%$ & $\mathrm{~N}$ & $\%$ \\
\hline Control & 5.58 & 5.2 & 3.08 & 2.6 & 11 & 91.7 & 1 & 8.3 & 10 & 83.3 & 2 & 16.7 \\
\hline Group-1 & 4.9 & 5.5 & 3.43 & 2.7 & 18 & 85.7 & 3 & 14.3 & 20 & 95.2 & 1 & 4.8 \\
\hline Group-2 & 3.84 & 3.6 & 2.53 & 1.6 & 11 & 84.6 & 2 & 15.4 & 8 & 61.5 & 5 & 38.4 \\
\hline $\begin{array}{l}\text { P.value } \\
\text { Significance }\end{array}$ & $\begin{array}{l}0.6 \\
\text { NS }\end{array}$ & & $\begin{array}{l}0.6 \\
\text { NS }\end{array}$ & & $\begin{array}{l}0.8 \\
\text { NS }\end{array}$ & & & & $\begin{array}{l}0.04 \\
\mathrm{~S}\end{array}$ & & & \\
\hline
\end{tabular}

Table- 2: statistical analysis among different groups according to duration, size, pain and erythema in second visit.

\begin{tabular}{|c|c|c|c|c|c|c|c|c|c|c|c|c|}
\hline \multirow{3}{*}{ Groups } & \multicolumn{2}{|c|}{ Duration(days) } & \multicolumn{2}{|c|}{$\operatorname{Size}(\mathrm{mm})$} & \multicolumn{4}{|c|}{ pain } & \multicolumn{4}{|c|}{ erythema } \\
\hline & \multirow[t]{2}{*}{ Mean } & \multirow{2}{*}{ SD } & \multirow[t]{2}{*}{ Mean } & \multirow[t]{2}{*}{ SD } & \multicolumn{2}{|c|}{ positive } & \multicolumn{2}{|c|}{ negative } & \multicolumn{2}{|c|}{ positive } & \multicolumn{2}{|c|}{ negative } \\
\hline & & & & & $\mathrm{N}$ & $\%$ & $\mathrm{~N}$ & $\%$ & $\mathrm{~N}$ & $\%$ & $\mathrm{~N}$ & $\%$ \\
\hline Control & 6.67 & 6.1 & 2.29 & 2.3 & 6 & 50.0 & 6 & 50.0 & 7 & 58.3 & 5 & 41.7 \\
\hline Group-1 & 6.71 & 6.03 & 2.48 & 2.2 & 7 & 33.3 & 14 & 66.7 & 12 & 57.1 & 9 & 42.9 \\
\hline Group-2 & 3.38 & 2.6 & 1.6 & 1.8 & 4 & 30.7 & 9 & 69.2 & 4 & 30.7 & 9 & 69.2 \\
\hline $\begin{array}{l}\text { P. value } \\
\text { Significance }\end{array}$ & $\begin{array}{l}0.1 \\
\text { NS }\end{array}$ & & $\begin{array}{l}0.1 \\
\text { NS }\end{array}$ & & $\begin{array}{l}0.5 \\
\text { NS }\end{array}$ & & & & $\begin{array}{l}0.2 \\
\text { NS }\end{array}$ & & & \\
\hline
\end{tabular}


Table-3: statistical analysis among different groups according to duration, size, pain and erythema in third visit.

\begin{tabular}{|c|c|c|c|c|c|c|c|c|c|c|c|c|}
\hline \multirow{3}{*}{ Groups } & \multicolumn{2}{|c|}{ Duration(days) } & \multicolumn{2}{|c|}{ Size $(\mathrm{mm})$} & \multicolumn{4}{|c|}{ pain } & \multicolumn{4}{|c|}{ erythema } \\
\hline & \multirow[b]{2}{*}{ Mean } & \multirow[b]{2}{*}{ SD } & \multirow{2}{*}{$\begin{array}{l}\text { Mea } \\
n\end{array}$} & \multirow{2}{*}{ SD } & \multicolumn{2}{|c|}{ positive } & \multicolumn{2}{|c|}{ negative } & \multicolumn{2}{|c|}{ positive } & \multicolumn{2}{|c|}{ negative } \\
\hline & & & & & $\mathrm{N}$ & $\%$ & $\mathrm{~N}$ & $\%$ & $\mathrm{~N}$ & $\%$ & $\mathrm{~N}$ & $\%$ \\
\hline Control $^{1}$ & 5.83 & 3.1 & 1.76 & 1.0 & 0 & 0.0 & 6 & 100 & 1 & 20.0 & 5 & 80.0 \\
\hline Group-1 $^{1}$ & 3.75 & 3.8 & 1.85 & 1.5 & 2 & 16.7 & 10 & $83 . .3$ & 3 & 25.0 & 9 & 75.0 \\
\hline Group-2 & 1.92 & 3.2 & 0.57 & 1.1 & 0 & 0.0 & 13 & 100 & 1 & 7.7 & 12 & 92.3 \\
\hline $\begin{array}{l}\text { P. value } \\
\text { Significance }\end{array}$ & $\begin{array}{l}0.08 \\
\text { NS }\end{array}$ & & $\begin{array}{l}0.1 \\
\text { NS }\end{array}$ & & $\begin{array}{l}0.1 \\
\mathrm{NS}\end{array}$ & & & & $\begin{array}{l}0.5 \\
\mathrm{NS}\end{array}$ & & & \\
\hline
\end{tabular}

\section{Discussion:}

The low energy laser stimulates DNA-RNAprotein system and raise mitotic activity of cell (14). This occurs through modification of cellular homeostasis of the mitochondria promoting a cascade of events in the respiratory chain of some mediators that permit absorption of light ${ }^{(11,15)}$, that lead to increase in mitochondrial content of ATP, and changes in ultrastructure of organelles. These changes in mitochondria promote cell division (16). This results in a more rapid epithelialization and regeneration of mucous membrane in the area of the lesion ${ }^{(17)}$. In Kashmoola et al study ${ }^{(12)}$, LLLT (Ga-As diode laser at $904 \mathrm{~nm}$ wavelength, continuous mode) was used. This has been used in treatment of RAU and explained that laser radiation at dose $1.5 \mathrm{~J}$ in single dose or two doses did not significantly affect the normal time of healing of RAU.

Topical triamcinolone is a glucocoticoid that has anti-inflammatory and anti proliferative effects. It diffuses into the cell receptors translocate to the nucleus where they can up regulate gene transcription by the dimerising on specific DNA response elements recruiting co-activator proteins, but can also oppose other transcription factor function ${ }^{(8,9)}$.

Statistically between the groups, there are no significant differences in the effect of these methods of treatment. However the relief of symptoms associated with recurrent aphthous ulcer may or may not correspond to clinical improvement.

Erythema occurs as a reaction to inflammation and high vascularization of the lesions $^{(2,3)}$. The clinical observation of erythematus halo around the ulcerative lesion was decreased in all cases of study groups. This is indicative of a decrease in the inflammatory reaction in the ulcerative area. In other words, the inflammatory cell infiltration was less prominent. But comparing these two study groups with control group, the result shows no significant relation between them. The laser light shows activation of suppressor T-lymphocyte ${ }^{(11)}$ which inhibits B-lymphocytes from antibody production and then decreased production of histamine and kinins that are responsible for inflammation ${ }^{(11)}$. 
On the other hand, the mechanism of action of triamcinolone acetonide kenalog results partly from vasoconstriction; the vasoconstrictions may be a direct or indirect effect exerted by the reduction of catecholamine, prostaglandin, or histamine levels at a target cell sites ${ }^{(8,9)}$. The anti-inflammatory effects of triamcinolone acetonide kenalog also may result from interference with the migration of polymorph nuclear leukocytes through the capillary walls and from decreased and adherence of WBCs to the capillary endothelium. This drug also exerts anti-inflammatory effects by interfering with the function of lymphocytes and macrophages and by decreasing the action of lymphokines. The glucocorticoids also decrease cell membrane permeability, impair the release of toxins or lysosomal enzymes, and inhibit the release or action of other chemical mediators during the inflammatory process. These mediators normally contribute to increase vascular permeability and subsequent changes including oedema, leukocyte migration and fibrin deposition.

However, the complexity of wound healing and vast biochemical mediators and cellular factors that modulate the process makes it unscientific to compare results when different method of therapy are used in the experiments along with varied tissue molecules like mucosa, different animal models, and different culture media ${ }^{(12)}$. Also the same idea is when comparing LLLT with topical drug therapy.

\section{Conclusion:}

RAU is self -limiting and there is no treatment to be curative permanently, therefore, treatments are directed only to reduce pain and maintain function during attacks. LLLT and triamcinolone kenalog can be used but there is no superior difference in clinical effects between these two methods.

\section{References:}

1. Rennie J, Reade P, Hay K, et al: recurrent aphthous stomatitis. Br. Dent. J.; 1985:159: 316-7.

2. Greenberg $\mathrm{M}$ : ulcerative, vesicular and bullous lesions. In Burket's Oral Medicine, diagnosis and treatment. $10^{\text {th }}$. Edition, Greenberg M. and Glick M.(eds.). BC Decker Inc. Spain, 2003:50-84.

3. Field $A$ and Longman $L$ : recurrent aphthous stomatitis.. In Tyldesley's Oral Medicine, $5^{\text {th }}$ edition. Oxford University press; 2003: 52-58.

4. Savage N, Seymour G, Kruger B: Tlymphocyte subset changes in recurrent aphthous stomatitis. Oral Surg Oral Med Oral Pathol; 1985:60: 175-81.

5. Sapp J, Eversole L, Wysocki G: recurrent aphthous stomatitis. In Contemporary Oral and Maxillofacial Pathology .Mosby, Inc.; 2002: 245-49.

6. Barrons R: treatment strategies for recurrent oral aphthous ulcers. Am. J. Health-syst. Pharm. 2001: 58: 41-53.

7. Vincent S, Lilly G: clinical, historic and therapeutic features of aphthous stomatitis: literature review and open clinical trial employing steroids. Oral Surg. Oral Med. Oral Pathol. 1992: 74: 79-86.

8. Baer CL and Williams BR: corticosteroid and other immune suppressive agents. In clinical pharmacology and nursing. $3^{\text {ed }}$ edition. Springhouse; 1996:966-969. 
9. Laurance $D$, Bennett $P$, Brown M: adrenal corticosteroids, antagonists, and corticotrophin. In Clinical Pharmacology. $9^{\text {th }}$ edition. Churchill Livingstone; Spain. 2003:663-677.

10. Howell R, Cohen D, Powell G, et al: the use of low energy laser therapy to treat aphthous ulcers. J Am Dent Assoc. 1988: 119: 16-18.

11. Abt A: biostimulation and photodynamic therapy. In Laser in Dentistry. Misrendino L. and Pick R.(eds.), Quintessence Publishing Co., Inc., 1995:247-57.

12. Kashmoola M, Salman $\mathrm{H}$ and Al-Waez M: clinical effect of low level laser therapy on healing of recurrent aphthous ulcer and oral ulceration in Behcets disease. Journal of Baghdad College of Dentistry; 2005:17(2): 36-40.

13. Abd El-Sattar E, Saudi $\mathrm{H}$ : comparative evaluation of low level laser therapy versus jogel in the treatment of RAU: a clinical and digital image analysis study.
Official Journal of the Egyptian Dental Association.2002: 48: 2227.

14. Kreisler $M$, Christoffer $A$, et al : effect of low level Ga-Al-As laser irradiation on the proliferation rate of human periodontal ligament fibroblasts. J. Clin. Periodontol. 2003: 30(4): 353-58.

15. Karu $\mathrm{T}$ : molecular mechanism of the therapeutic effect of low intensity laser irradiation. Lasers in the Life Sciences 1988: 2: 53-74.

16. Basford J: laser therapy: scientific basis and clinical role. Orthopedics. 1993: 16: 541-47.

17. Haas $A$, Isseroff $R$, Wheeland $R$, et al : low energy $\mathrm{He}-\mathrm{Ne}$ laser irradiation increase the motility of cultured human keratinocytes. J. Invest. Dermatol. 1990: 94: 822-26. 